Nordisk Tidsskrift for Kriminalvidenskab 2006

\title{
Polisers bruk aV SKJutvapen i Norge och Sverige
}

Av PROFESSOR JOHANNES KNUTSSON

There seems to be an almost universal tendency to assume that police work is getting ever more dangerous and that the police, as a consequence, have to use their firearms more frequently. A special case is the occurrence of "cascading events", i.e., incidents in which a single action triggers multiple, often serious, consequences. Trends in police officers' use of firearms in Norway and Sweden during the last few decades are examined. Norway has an unarmed force while Sweden has a regularly armed police force. Norwegian police officers are trained in the use of firearms, but have to get authorisation from a chief of police before they may arm themselves. Their arms are either stored in police stations or are stowed unloaded in sealed bags in patrol cars. After an incident in which two officers were shot to death in Norway in 1998, the number of cases in which police draw firearms to threaten suspects tripled to about 60 incidents per year. However, incidents where police open fire have remained stable at about 2 to 3 cases per year for the entire Norwegian police force. The consequences of these shootings in terms of injured or killed civilians have also been stable at about one civilian injured per year. In 1999, two Swedish police officers were murdered with their own service weapons by three bank robbers. Yet this event seems to have had no effect on the frequency with which Swedish police officers draw their firearms. During an average year in Sweden, police officers fire their weapons in connection with about 25 incidents, injure civilians in about 7 incidents, and kill about one civilian. For both countries, the stability in the frequency of shootings is striking.

Polisens användning av skjutvapen är utsatt för stor uppmärksamhet. Den särpräglade norska skjutvapenpolicyn för polisen med en rutinmässigt obeväpnad polis brukar efter dramatiska händelser med skottlossning hamna i strålkastarljuset. Hos somliga debattdeltagare verkar det finnas ett antagande om att det pågår en obönhörlig utveckling i samhället som innebär att polisen allt oftare tvingas använda sina skjutvapen. Detta skulle heller inte vara unikt för Norge, utan vara ett skeende som pågår även $\mathrm{i}$ andra länder.

\footnotetext{
* Title in English: Police Use of Firearms in Norway and Sweden. Original in Swedish.
} 
Om detta är sant blir den naturliga frågan om inte Norge skulle bli tvungen att överge sin filosofi och att norsk polis i likhet med de flesta andra länder även skulle få en regelmässigt beväpnad polis.

Det kan därför vara på sin plats att ta fram ett grundläggande faktaunderlag för att belysa utvecklingen av skjutvapenbruket inom polisen. Förutom uppgifter under de senaste decennierna från Norge redovisas även utvecklingen för ett annat nordiskt land, nämligen Sverige.

Följande frågor kommer att behandlas:

- Har polisens bruk av skjutvapen ökat?

- Skjuter poliser allt oftare?

- Blir allt fler skadade och dödade av poliser?

- Kommer fler poliser till skada i samband med incidenter där de brukar skjutvapen?

- Hur ser utvecklingen i Sverige ut med sin rutinmässigt skjutvapenbeväpnade polis?

Den centrala frågan är således om det verkligen finns påtagliga långsiktiga trender och tendenser i polisens bruk av skjutvapen och konsekvenserna av det.

När det gäller förändringar utgör "cascading event" ett specialfall. ${ }^{1}$ I stället för en mer kontinuerlig utveckling leder sådana händelser till språngvisa förändringar. Begreppet har sitt ursprung i forskningen och diskussionen om terrorism och står för konsekvenser av en enstaka händelse. Ett tydligt exempel utgör terroristdådet i New York den 11 september 2001, som allt sedan dess präglat ett skeende på världsbasis. Effekten av en "cascading event" är således en påtaglig förändring av ett tillstånd till ett annat och inte en gradvis anpassning.

Ett exempel från polisens område är införandet av en ny taktik eller policy. Den danska polisen förändrades till exempel från en obeväpnad till rutinmässigt beväpnad poliskår år 1965 efter en incident där fyra poliser sköts till döds (Holmberg, 2005). Både i Norge och Sverige inträffade två tragiska händelser under senare delen av 1990-talet med poliser som sköts till döds. Går det att spåra ett inflytande på utvecklingen av dessa incidenter? 


\section{Polisers bruk av skjutvapen}

Bruket av skjutvapen är en del av polisens vålds- eller maktutövning och måste ses efter en glidande skala (se Skolnick och Fyfe, 1993). Det är således en alldeles för enkel uppfattning att polisers bruk av skjutvapen endast skulle innebära skottlossning (se Knutsson, 2005). Även hot från polisen om att skjuta måste tas med i bilden när polisers vapenanvänding diskuteras eftersom polisen kan uppnå sitt syfte enbart med hotet om att avlossa skott. Det är dock en betydligt enklare uppgift att fastställa om ett skott har gått av eller inte, än att entydigt avgöra om ett hot förekommit. Det är viktigt att ha en tydlig definition på vad som skall

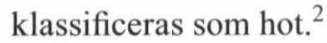

\section{Skillnader i skjutvapenpolicy}

Alla blivande poliser i såväl Norge som Sverige får utbildning i att använda skjutvapen under grundutbildningen. En skillnad är att polisstudenterna i Norge även utbildas i att använda förstärkningsvapen.

I Norge används en revolver av modellen Smith \& Wesson cal. 38. Standardammunitionen är helmantlad. Tjänstevapnet i Sverige är en pistol av modellen Sig Sauer 9 mm. Från år 2003 använder svensk polis expanderbar ammunition. Båda länderna har samma slags förstärkningsvapen, en kpist av märket MP $5 .^{3}$

I princip får norska och svenska poliser bruka skjutvapen i samma slags situationer. ${ }^{4}$ Den fundamentala skillnaden är att norsk polis som huvudregel endast får beväpna sig med skjutvapen efter order av en polischef. Vapnen finns tillgängliga antingen inne på polisstationer eller i så kallad framskjuten depå. Det innebär att vapnen förvaras oladdade och sigillförsedda i polisbilar.

I praktiken utgörs skillnaden av tillgänglighet av skjutvapen. Svenska poliser har omedelbar tillgång, medan norska poliser normalt sett har det efter en tidsfördröjning. Denna fördröjning kan röra sig om minuter till uppemot timmar. Detta innebär att det vid förutsägbara situationer inte finns någon praktisk skillnad. En beväpnad insatsstyrka organiseras som tar sig an uppgiften. Skillnaden blir däremot stor vid oförutsägbara hastigt uppkomna situationer. Svensk polis har då möjlighet att bruka skjutvapen; en möjlighet som normalt sett inte står norsk polis till buds. Den norska taktiken går då i princip ut på att frysa situationen, erhålla en beväpningsorder och att organisera en väpnad styrka för att lösa uppgiften. Därmed skapas ett större utrymme för möjligheter att lösa situationerna utan skottlossning

$\mathrm{Nu}$ är det dock inte skillnaden i skjutvapenbruk länderna emellan som är utgångspunkten för denna undersökning. ${ }^{5}$ Den är helt inriktad på utvecklingen av polisens skjutvapenbruk för att se om det i det hänseendet finns likheter eller olikheter. Om utvecklingen är likartad kan det peka på att det är mer generella mekanismer som är i görningen. 


\section{Data}

Norska data har inhämtats från inrapporteringar och sammanställningar över inrapporterade fall av vapenbruk till Politidirektoratet. ${ }^{6}$ Uppgifterna avser perioden 1990 till 2004. När det gäller hot med skjutvapen kan det finnas fall där hot förekommit, men där det inte inrapporterats. De skulle i så fall ingå i mörktalet. Bland annat med tanke på att det ofta varit fler poliser på plats, är det inte särskilt troligt att det skulle vara särskilt vanligt med denna typ av regelbrott. En annan felkälla är att fall inrapporteras där något reellt hot med skjutvapen inte förekommit. Det kan således finnas en viss osäkerhet i uppgifterna. Knappast något talar dock för att dessa felkällor, som kan innebära under- respektive överrapportering, skulle ha förändrats nämnvärt över tid.

I Sverige skall endast incidenter med skottlossning rapporteras till Rikspolisstyrelsen, vilket innebär att det inte är möjligt att på rutinbasis fastställa i vilken utsträckning svenska poliser brukat skjutvapen för hot.

Med inrapporteringar till Rikspolisstyrelsen som huvudsaklig källa har före detta kommissarie Sven Silverudd byggt upp en databas med alla händelser som inträffat sedan 1985. Denna bas är datakälla för denna undersökning, som för svensk del sträcker sig till 2002. ${ }^{7}$ Några av analyserna spänner över perioden 1985-1998. Källan är i det sammanhanget Knutsson och Strype (2002).

\section{Den norska utvecklingen 1990-2004}

Mellan 1990 och 1996 varierade antalet fall där norska poliser använt skjutvapen i tjänsten för hot från 15 till 29 incidenter per år. Vid slutet av 1990-talet skedde en stark uppgång. Antalet inrapporterade fall nästan tredubblades på bara några år. Under början av 2000-talet stabiliserades nivån till cirka 70 fall årligen (se figur 1).

Figur 1. Antal incidenter där polis under tjänstutövning använt skjutvapen för hot. Norge 1990-2004.

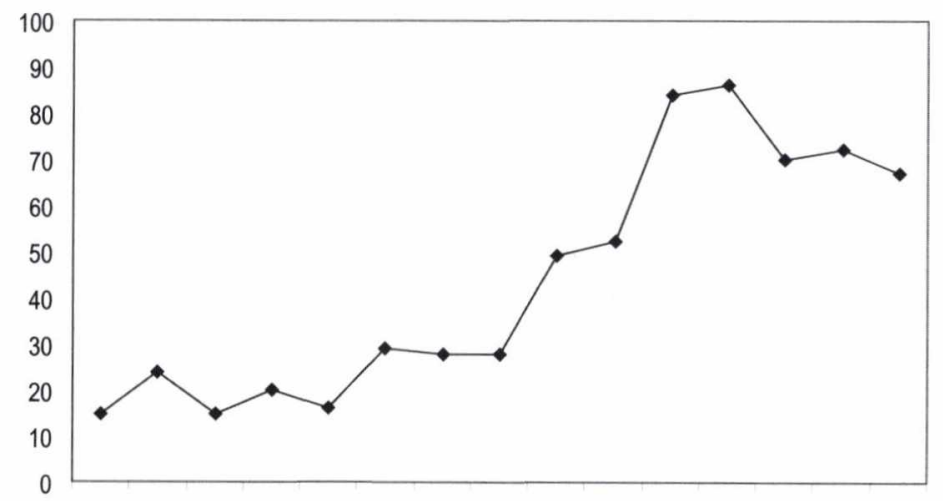

199019911992199319941995199619971998199920002001200220032004 
För antalet incidenter där skott avlossades ser utvecklingen däremot annorlunda ut. Fallen varierade mellan ett och fem och det finns inga tendenser till ökningar. Möjligen kan en nedåtgående tendens skönjas (se figur 2).

Figur 2. Antal incidenter där polis under tjänstutövning avlossat skott. Norge 1990-2004.

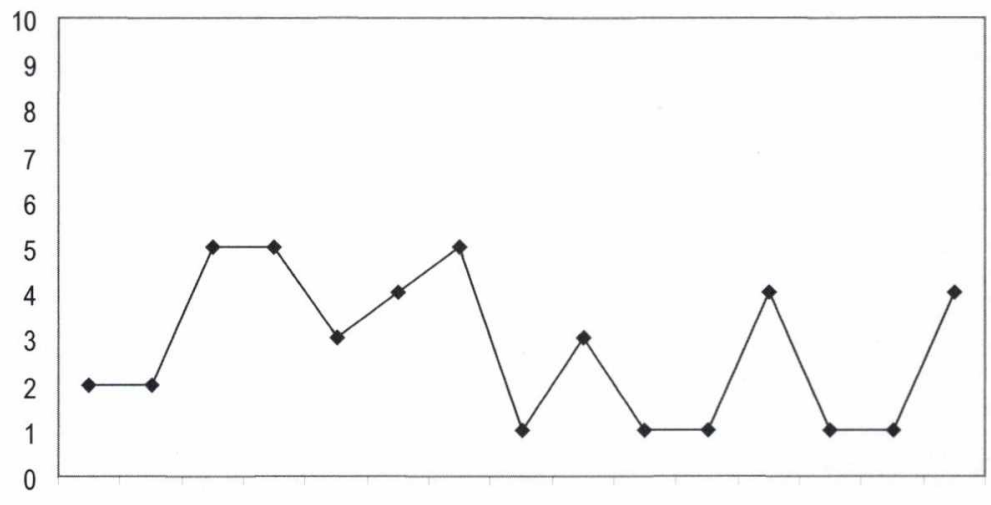

199019911992199319941995199619971998199920002001200220032004

Till skillnad från utvecklingen avseende hot, finns således ingen uppgång när det gäller incidenter med skottlossning. Tvärtom är nivån något lägre från senare delen av 1990-talet. Vad kan ligga bakom denna olika utveckling med förhöjd nivå av hot med skjutvapen som dock inte återspeglas när det gäller skjutningarna?

\section{Austbo 1998 - cascading event?}

I mars månad år 1998 blev två poliser ihjälskjutna i Austbø av en man med psykiska problem. Poliserna var beväpnade, men var inte i position för att kunna använda sina skjutvapen vare sig för hot eller för att avlossa skott.

Den tragiska händelsen fick naturligtvis stor uppmärksamhet i massmedia och gav upphov till en debatt om vården av personer med psykiska problem. Självklart präglades även polisen av det inträffade. Som en förklaring till uppgången av inrapportat skjutvapenbruk har händelsen i Austbø blivit nämnd. Detta skulle således kunna vara ett fall av "cascading event".

För att undersöka det eventuella inflytandet har månadsvisa uppgifter över antalet incidenter med hot respektive skottlossning tagits fram. Därefter har tester skett för att undersöka om medelvärdena i vapenbruk före och efter Austbøhändelsen skiljer sig signifikant. ${ }^{8}$ 
Som framgår av figur 3, skedde en uppgång i skjutvapenanvändning efter Austbøincidenten. Det månatliga medelvärdet för inrapporterade hot steg från 1,93 till 5,78. Det är således fråga om en trefaldig ökning.

Figur 3. Antal incidenter där polis under tjänstutövning hotat med skjutvapen eller avlossat skott, januari 1991 till december 2004. Månadsvisa värden. Aritmetiskt medelvärde med $95 \%$ konfidensintervall före och efter Austbøincidenten mars 1998 markerade. ${ }^{9}$

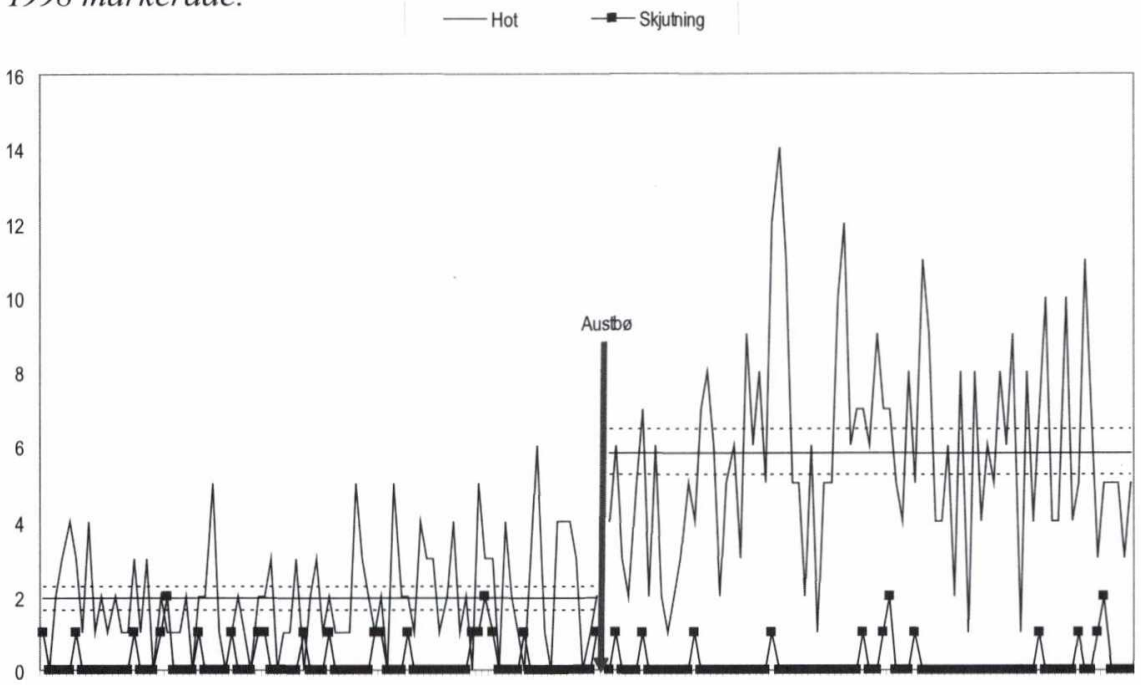

Uppgången av antalet incidenter med hot är statistiskt signifikant. Den smärre nedgången när det gäller skjutningar ligger dock inom ramen för slumpvariationen (se tabell 1).

Tabell 1. Medelvärden januari 1991 till februari 1998, april 1998 till december 2004 och signifikanstest (ANOVA) av skillnad i medelvärde. Incidenter där polis i tjänst använt vapen för hot, avlossat skott och andel (\%) incidenter där skottlossning ägt rum. Månadsvisa värden, Norge.

\begin{tabular}{llll}
\hline Kategori & $\begin{array}{l}\text { Medelvärde } \\
\text { jan 91-feb 98 }\end{array}$ & apr 98-dec 04 & \\
\hline Hot & 1,93 & 5,78 & $* * *$ \\
Skjutning & 0,26 & 0,17 & e.s \\
Andel (\%) med eld & 12,0 & 2,48 & $* * *$ \\
\hline
\end{tabular}

e.s. $=$ ej signifikant. ${ }^{*} \mathrm{p} \leq 0,05,{ }^{* *} \mathrm{p} \leq 0,01,{ }^{* * *} \mathrm{p} \leq 0,001$ 
Konsekvensen av uppgången av hoten och den stabila nivån på skjutningarna är att andelen incidenter med skottlossning minskat signifikant - från 12 till cirka 2,5 procent.

En möjlig förklaring till detta mönster är att polisen ändrat sin taktik och att det inte skett en uppgång i antalet kritiska incidenter. Om antalet kritiska situationer ökat, borde det rimligen även ha inträffat en ökning av antalet fall där polis avlossat skott, något som dock inte skett. Det kan således vara så att det numera i större utsträckning brukas skjutvapen för hot i situationer som polisen tidigare löste utan något skjutvapenbruk. I så fall rör det sig om en anpassning där poliser för att känna sig på den säkra sidan oftare använder sig av skjutvapnen.

Enligt dessa resonemang skulle händelsen i Austbø haft en effekt på polisernas uppträdande men inte på tillfällen med skjutningar.

\section{Skadade och dödade motparter}

Mellan 1990 och 2004 sköts fyra personer till döds i samband med polisingripanden. Under samma tidsrymd skadades motparter i tolv incidenter där poliser avlossat skott, vilket innebär knappt en person per år (se figur 4).

Figur 4. Antal incidenter med skadad eller dödad motpart. Norge 1990-2004.

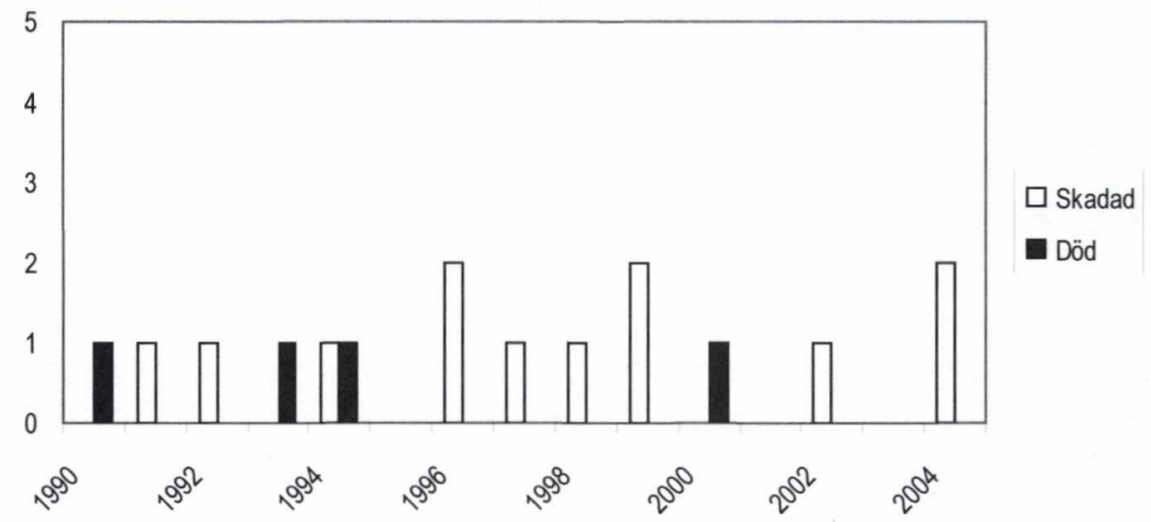

När det gäller antalet skadade och dödade motparter finns ingen som helst trend, vare sig $\mathrm{i}$ ökande eller minskande riktning. ${ }^{10}$

\section{Antal skadade och dödade poliser}

Under den följda perioden sköts en polis ihjäl i samband med en situation där poliser brukade skjutvapen. Dödsskjutningen inträffade när polisen ingrep vid ett rån i 
Stavanger år 2004. Den omkomne polisen hade tillgång till skjutvapen, men använde det inte själv. Det var en annan polis som sköt och skadade en av rånarna.

Däremot brukade inte polisen skjutvapen i samband med händelsen i Austbø, vare sig i en mer snäv eller vid betydelse av termen bruk.

\section{Den svenska utvecklingen 1985-2002}

Mellan 1985 och 2002 varierade det årligen inträffade antalet skjutningar från 19 till 35 (se figur 5). Trenden är svagt nedåtgående, men är inte signifikant.

Figur 5. Antal incidenter där polis under tjänstutövning avlossat skott. Sverige 1990-2004.

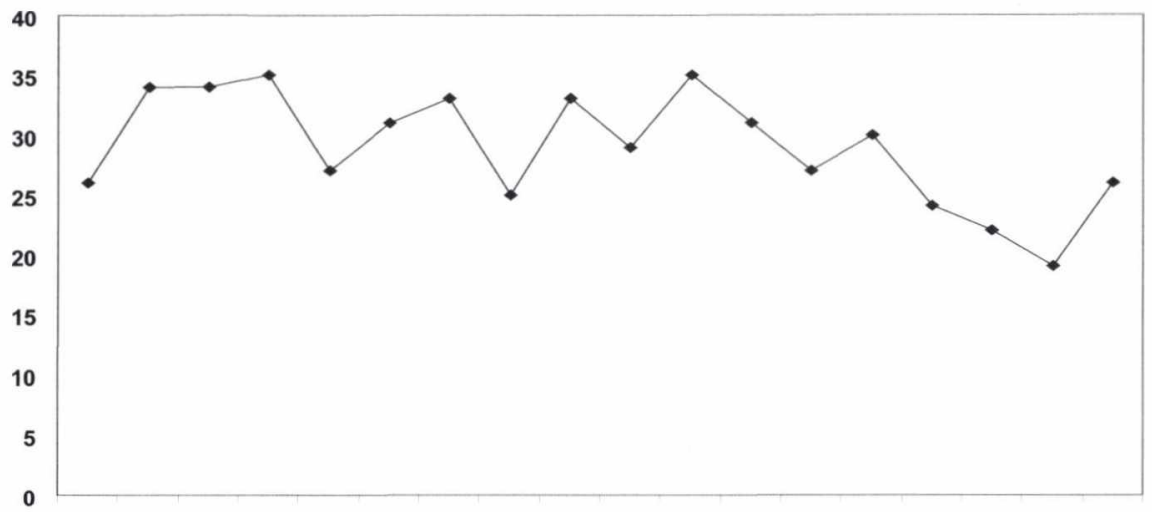

198519861987198819891990199119921993199419951996199719981999200020012002

Malexander 1999 - cascading event?

I maj 1999 blev två poliser som förföljde tre bankrånare inblandade i en skottväxling i Malexander, ett litet samhälle på den svenska landsbyggden. Händelsen slutade med att de båda poliserna sköts ihjäl med sina egna tjänstevapen av rånarna. Polismorden i Malexander blev intensivt täckt av massmedia. I den efterföljande debatten hävdades bland annat att incidenten hade en dramatisk effekt på polisens benägenhet att använda sina skjutvapen och att allt fler personer därefter blev skadade och ihjälskjutna av poliser. Det skulle således röra sig om en "cascading event".

För att undersöka om detta stämmer har en analys genomförts med månatliga data. Det genomsnittliga antalet incidenter där poliser avlossat skott, samt konsekvenserna av det, har jämförts före och efter händelsen i Malexander.

I motsats till vad som hävdats har det genomsnittliga antalet incidenter med skottlossning av poliser varit lägre efter morden i Malexander (se figur 6). 
Figur 6. Antal incidenter där polis under tjänstutövning avlossat skott, oktober 1995 till april 1999, juni 1999 till december 2002. Månadsvisa värden. Aritmetiskt medelvärde med $95 \%$ konfidensintervall före och efter Malexanderincidenten maj 1999 markerade.

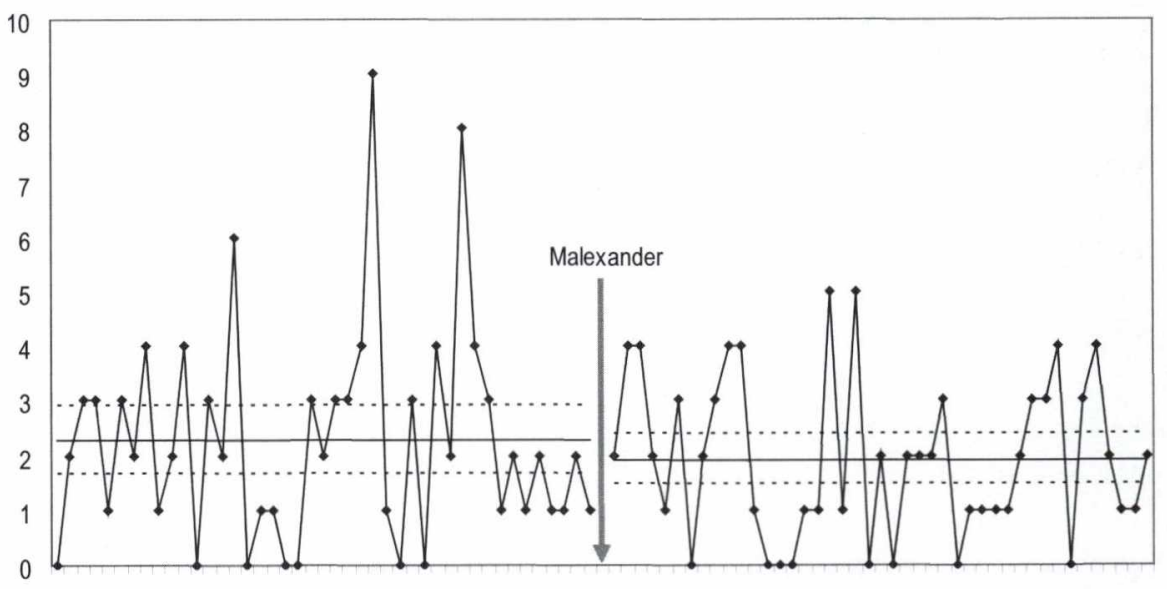

Det månatliga medelvärdet är för de 43 månaderna före händelsen 2,28 mot 1,93 för efterföljande period. Den smärre nedgången är dock inte statistiskt signifikant (se tabell 2).

Tabell 2. Medelvärden oktober 1995 till april 1999, juni 1999 till december 2002 och signifikanstest (ANOVA) av skillnad i medelvärde. Incidenter där polis i tjänst avlossat skott samt incidenter med skadade eller dödade motparter. Månadsvisa värden, Sverige.

\begin{tabular}{llll}
\hline & $\begin{array}{l}\text { Medelvärde } \\
\text { okt 95-apr 99 }\end{array}$ & jun 99-dec 02 & Sign. \\
\hline Skjutningar & 2,28 & 1,93 & e.s. \\
Skadade & 0,49 & 0,51 & e.s. \\
Dödade & 0,05 & 0,16 & e.s. \\
Skadade/dödade & 0,53 & 0,67 & e.s. \\
\hline
\end{tabular}

e.s. $=$ ej signifikant. ${ }^{*} \mathrm{p} \leq 0,05,{ }^{* *} \mathrm{p} \leq 0,01,{ }^{* * *} \mathrm{p} \leq 0,001$

Det genomsnittliga antalet skadade motparter är ungefärligen på samma nivå, medan det finns en ökning av antalet incidenter där personer dödats som en följd av polisens skottlossning. Skillnaden är dock inte statistiskt signifikant. 
Som regel är det olyckliga omständigheter som i den absoluta majoriteten av fallen leder till att beskjutna omkommer. Därför är det meningsfullt att analysera kategorierna skadade och döda sammantaget. Det något högre värdet efter incidenten i Malexander är inte statistiskt signifikant. Det finns således inget stöd för föreställningen att denna händelse fungerat som en "cascading event".

\section{Skadade och dödade motparter}

Genomsnittligt per år inträffade 7,1 incidenter där poliser skadade motparter sedan poliserna avlossat skott. Det finns ingen statistiskt signifikant trend (se figur 7).

Figur 7. Antal incidenter med skadad eller dödad motpart. Sverige 1985-2002.

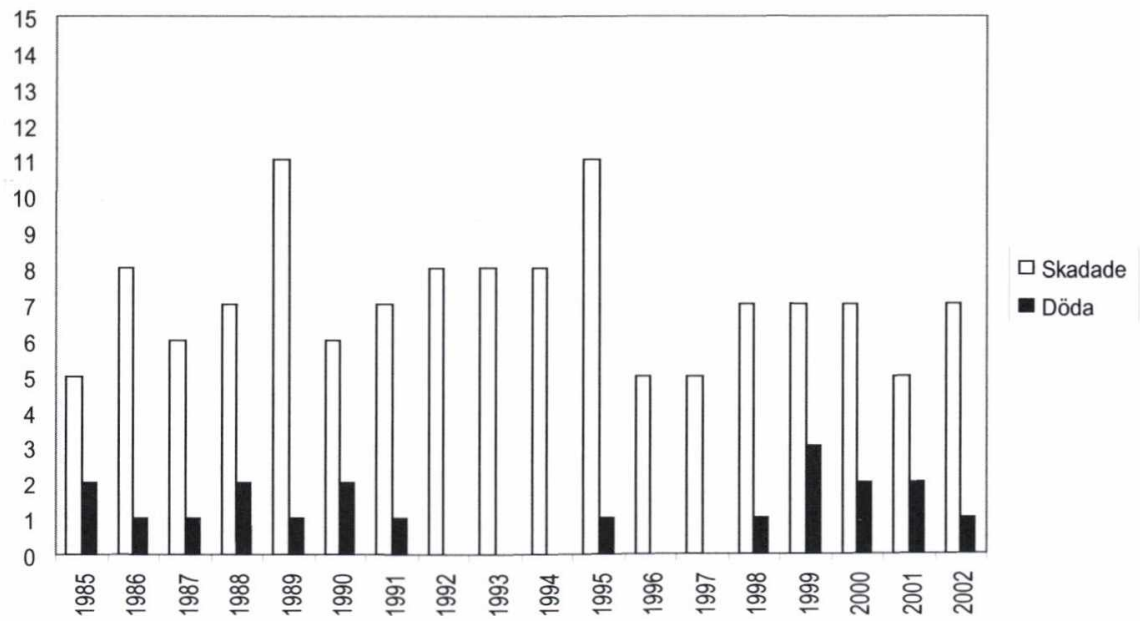

Antalet omkomna motparter varierar mellan noll och tre, med ett genomsnittligt värde om 1,1. Det finns ingen statistiskt säkerställd trend.

Antal skadade och dödade poliser

I genomsnitt inträffade 2,4 incidenter per år där poliser skadades eller omkom i samband med skottlossning från polisens sida. Det finns ingen statistiskt säkerställd trend (se figur 8). 
Figur 8. Antal incidenter där poliser öppnat eld och poliser skadats eller dödats. Sverige 1985-2002.

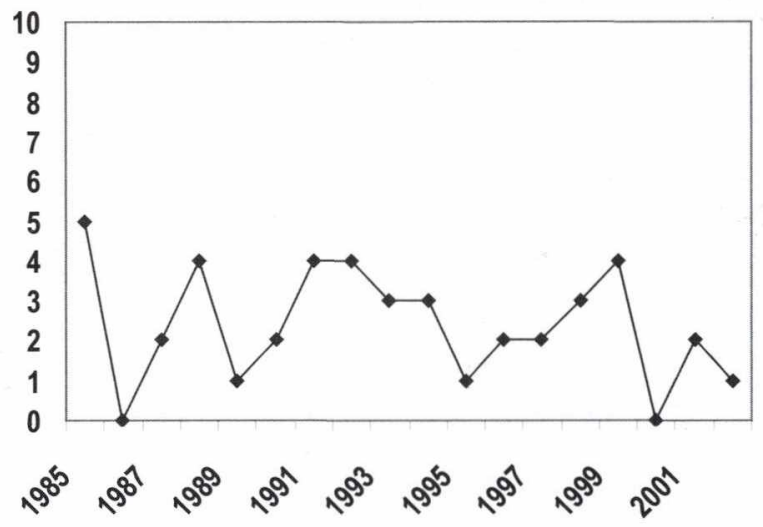

I en av incidenterna sköts två poliser till döds (Malexander). I övriga fall rörde det sig om icke dödliga skador.

När motparter skadas är orsaken kulor som avfyrats av polisen. För poliserna är skadebilden varierande. Ungefär en tredjedel av skadorna härrör från egna vådaskott. Andra har blivit skadade av knivar, yxor eller andra skarpa föremål. Några har blivit påkörda av bilar. Även om det är sällsynt, finns också skador från beskjutningar av motparter.

\section{Förändringar i strukturen?}

På det hela taget verkar det inte finnas några påtagliga trender när det gäller incidenter där poliser avlossat sina skjutvapen eller konsekvenserna av det. Det kan emellertid vara så att det finns förändringar i strukturen av händelserna som inte fångas upp eftersom data är på en aggregerad nivå.

Den vanligaste orsaken till att svenska poliser avfyrar sin skjutvapen är för att avvärja hot eller angrepp mot sig själva. Detta gäller för så gott som 80 procent av fallen. Dessa situationer kan delas in i sex olika underkategorier (Knutsson och Strype, 2002).

Kategorin befarat beväpnad handlar till exempel om att någon döljer sin hand i en jackficka och vägrar visa om han har ett vapen eller ej. Särskilt om beteendet förstärks med ett verbalt hot blir det en särdeles vansklig situation för polisen. Den enskilde polisen utgår då från att det kan röra sig om ett vapen och skjuter. 
Kategorin skjutvapen utgörs av situationer där skjutvapen förekommer oavsett om skott avlossas eller inte och oavsett om det handlar om riktiga vapen eller ej. Det räcker med någon som skjuter, hotar med att skjuta eller siktar med något som uppfattas vara ett skjutvapen. Utgångspunkten är hur den skjutande polisen uppfattar i situationen.

I kategorin klassificerad som hot med kniv eller tillhygge ingår situationer där poliserna är hotade med skarpa föremål. Hoten kan understrykas med åtbörder eller ord.

Kategorin angrepp med kniv eller annat farligt tillhygge består av situationer där poliserna är utsatta för direkta angrepp med kniv eller annat farligt tillhygge i form av yxa, spett, järnstång eller dylika föremål.

Till kategorin angrepp med fordon hör skjutepisoder där personer försöker köra på poliser. Även om personerna varit utrustade med vapen, är det fordonet som utgör det direkta hotet mot poliserna och som de försöker värja sig mot. Poliserna försöker att undkomma fordonet och skjuter oftast mot ett däck för att försöka få stopp på fordonet.

Testen av eventuella statistiskt signfikanta förändringar har genomförts med T-testet på så vis att materialet delats in i två delar varefter skillnader i medelvärden undersökts för de olika kategorierna. Resultatet framgår av tabell 3.

Tabell 3. Medelvärden 1985-1991 och 1992-1998 och test för skillnad i medelvärde efter typ av incident. Sverige 1985-1998.

\begin{tabular}{llll}
\hline Kategori & Medelvärde 85-91 & Medelvärde 92-98 & Sign. \\
\hline Befarat beväpnad & 7,57 & 3,57 & $* *$ \\
Skjutvapen & 5,14 & 4,29 & e.s. \\
Hot med kniv eller annat tillhygge & 3,86 & 4,14 & e.s. \\
Angrepp med kniv eller & 4,29 & 4,00 & e.s. \\
annat tillhygge & 3,00 & 5,71 & e.s. \\
Angrepp med fordon &
\end{tabular}

e.s. $=$ ej signifikant $* p \leq 0,05, * * p \leq 0,01, * * * p \leq 0,001$

En förändring har endast skett för en kategori, nämligen befarat beväpnad. Där har genomsnittsvärdet sjunkit från 7,57 incidenter per år till 3,57, vilket är en statistiskt säkerställd skillnad. Kategorin angrepp med fordon har ökat något, men uppgången är inte statistiskt signifikant. Slutsatsen blir att strukturen av händelserna som utlöser polisens skjutningar tycks ha varit tämligen stabil under den studerade perioden.

En invändning är att denna analys endast sträcker sig fram till 1998. Det ligger naturligtvis något i det, men det finns ingen uppgång att förklara efter detta år, utan det rör sig snarare om en nedgång som skulle söka sin förklaring. 


\section{Slutsats}

Under den tidsperiod som täcks i undersökningen är det endast en påtaglig förändring som inträffat. Den norska polisen verkar ha ändrat sin taktik efter händelsen i Austbø. Därefter använder polisen sina vapen oftare för hot, men, vilket är centralt, kommer inte oftare i situationer där skott avlossas. Dödsskjutningen i Malexander med två dödade poliser har inte följts av fler incidenter där poliser skjutit. Inte heller har fler skadats eller dödats. Snarare skjuter den svenska polisen något mer sällan. En möjlig förklaring till båda dessa tendenser är att polisen i sitt arbete $\mathrm{i}$ hög grad styrs av principen om försiktighet.

I övrigt kännetecknas nivåerna av stabilitet. Detta förhållandet utmärker inte bara Norge och Sverige. Även i Danmark är situationen likartad (Holmberg, 2005), liksom i Finland. I Finland genomfördes en genomgripande reform av polisens skjutvapenpolicy år 1997. En avsikt var att få till stånd ett mer restriktivt bruk av skjutvapen, något som även skett. Antalet skjutningar har minskat påtagligt sedan början av 1990-talet, för att därefter hamna på en lägre nivå (Åminne och Lounaskorpi, 2005).

Det mest iögonfallande resultatet är den konstans som rått de senaste decennierna både när det gäller händelser där polis under tjänstutövning skjutit och konsekvenserna av skottlossningen i form av skadade och dödade motparter. De fakta som presenterats i denna undersökning ger inget stöd för att det skulle pågå en illavarslande utveckling, åtminstone inte när det gäller polisens bruk av skjutvapen.

\section{Litteratur}

Holmberg, L. (2005). Politiets brug af skydevåben i Danmark. I: Knutsson, J. (red.) Polisens bruk av skjutvapen i Norden. Oslo: Politihøgskolen.

Knutsson, J. (2005). Polisens bruk av skjutvapen - det svenska exemplet. I: Knutsson, J. (red.) Polisens bruk av skjutvapen i Norden. Oslo: Politihøgskolen.

Knutsson, J. \& Strype, J. (2002). Polisens bruk av skjutvapen. Rapport 2002:1. Jönköping: Polishögskolan.

Knutsson, J. och Strype, J. (2003). Police Use of Firearms in Norway and Sweden - the significance of gun availability. Policing \& Society. Vol. 13 (4):429-439.

Knutsson, J. \& Norée, A. (2005). Polisers bruk av skjutvapen i Norden - en jämförelse. I: Knutsson, J. (red.) Polisens bruk av skjutvapen i Norden. Oslo: Politihøgskolen.

Norée, A. (2000). Laga befogenhet. Polisens rätt att använda våld. Stockholm: Jure. Norée, A. (2004). Polisers rätt att skjuta. Stockholm: Norstedts Juridik.

Norée, A. (2005). Svenska polisers rätt att skjuta. I: Knutsson, J. (red.) Polisens bruk av skjutvapen $i$ Norden. Oslo: Politihøgskolen.

Myhrer, T-G. (2005a). Politiets bruk av skytevåpen - Rettslige problemstillinger. I: Knutsson, J. (red.) Polisens bruk av skjutvapen i Norden. Oslo: Politihøgskolen. 
Myhrer, T-G. (2005b). ".....som siste utvei" Rettslige rammer for politiets bruk av skyte-våpen. Oslo: Universitetsforlaget.

Skolnick, J. H. \& Fyfe, J. (1993). Above the law. Police and the excessive use of force. New York: Free Press.

Strype, J. och Knutsson, J. (2002). Politiets bruk av skytevåpen. PHS Forskning 2002:1. Oslo: Politihøgskolen.

Åminne, C-G. och Lounaskorpi, J. (2005). Polisens bruk av skjutvapen - det finska exemplet. I: Knutsson, J. (red.) Polisens bruk av skjutvapen i Norden. Oslo: Politihøgskolen.

\section{Noter:}

1 Begreppet "cascading event" har i polissammanhang använts av Maki Haberfield.

2 I Finland definieras skjutvapenhot på följande sätt: "Hot med vapen avser riktande av vapnet så att den person som vapnet riktas mot, med hänsyn till allmän livserfarenhet, har grundad anledning att förmoda att han eller hon blir föremål för de allra strängaste maktmedlen om inte den befallning efterföljs som polismannen förstärker med vapnet” ( $\AA$ minne och Lounaskorpi, 2005 s. 66). Däremot finns i den norska instruktionen en viss otydlighet om vad hot utgör (Myhrer, 2005a s. 86).

3 När det gäller de speciella insatstyrkor som finns i båda länderna är förhållandena vad gäller utrustning annorlunda. I denna undersökning utgör det generella utgångspunkten.

4 För norsk del, se Myhrer (2005a; 2005b) och för svensk del, se Norée $(2000 ; 2004 ; 2005)$.

5 Det är tämligen givet att en större tillgång till skjutvapen leder till en större användning. Mellan 1999 och 2002 uppgick den relativa skillnaden till drygt fem med hänsyn tagen till befolkningstalen, se Knutsson och Norée (2005). Det innebär att svensk polis sköt drygt fem gånger oftare än norsk. När det gäller skadade motparter uppgick skillnaden till cirka tre gånger. För en mer ingående diskussion om skillnaderna länderna emellan se Knutsson och Strype (2002; 2003) eller Strype och Knutsson (2002).

6 Innan Politidirektoratets tillblivelse var Politiavdelingen vid Justisdepartement inrapporteringsinstans. Uppgifterna fram till år 1999 har insamlats av Jon Strype vid den norska polishögskolans forskningsavdelning,

6 Vid Rikspolisstyrelsen har sedan en lång tid en nyutvecklad inrapporteringsrutin succesivt införts. Uppgifter från senare år finns dock ännu inte tillgängliga.

7 Testet har genomförts med ANOVA-analyser.

8 Konfidensintervallet är ett mått på osäkerheten i skattningen av medelvärdet.

9 Testet har skett med T-test. Perioden har delats i två delar för att se om skillnader i medelvärde är statistiskt säkerställda. Om inget annat anges har signifikanstesterna genomförts på detta sätt.

Adress:

Politihøgskolen

$\mathrm{Pb} 5027$ Majorstua

0301 Oslo

Norge

e-post: johannes.knutsson@phs.no 